\title{
Joint Optimization Approach of Maintenance and Production Planning for a Multiple-Product Manufacturing System
}

\author{
Lahcen Mifdal, ${ }^{1,2}$ Zied Hajej, $^{1}$ and Sofiene Dellagi ${ }^{1}$ \\ ${ }^{1}$ LGIPM, Université de Lorraine, Île de Saulcy, 57045 Metz Cedex 01, France \\ ${ }^{2}$ Ecole Polytechnique d'Agadir, Universiapolis, Bab Al Madina Tilila, 80000 Agadir, Morocco \\ Correspondence should be addressed to Lahcen Mifdal; lahcen.mifdal@univ-lorraine.fr
}

Received 31 October 2014; Accepted 2 December 2014

Academic Editor: Felix T. S. Chan

Copyright (c) 2015 Lahcen Mifdal et al. This is an open access article distributed under the Creative Commons Attribution License, which permits unrestricted use, distribution, and reproduction in any medium, provided the original work is properly cited.

\begin{abstract}
This paper deals with the problem of maintenance and production planning for randomly failing multiple-product manufacturing system. The latter consists of one machine which produces several types of products in order to satisfy random demands corresponding to every type of product. At any given time, the machine can only produce one type of product and then switches to another one. The purpose of this study is to establish sequentially an economical production plan and an optimal maintenance strategy, taking into account the influence of the production rate on the system's degradation. Analytical models are developed in order to find the production plan and the preventive maintenance strategy which minimizes sequentially the total production/inventory cost and then the total maintenance cost. Finally, a numerical example is presented to illustrate the usefulness of the proposed approach.
\end{abstract}

\section{Introduction}

Manufacturing companies must manage several functional capacities successfully, such as production, maintenance, quality, and marketing. One of the keys to success consists in treating all these services simultaneously. On the other hand, the customer satisfaction is one of the first objectives of a company. In fact, the nonsatisfaction of the customer on time is often due to a random demand or a sudden failure of production system. Therefore, it is necessary to develop maintenance policies relating to production, reducing the total production and maintenance cost. One of the first actions of decision-making hierarchy of a company is the development of an economical production plan and an optimal maintenance strategy.

It is necessary to find the best production plan and the best maintenance strategy required by the company to satisfy customers. This is a complex task because there are various uncertainties due to external and internal factors. External factors may be associated with the inability to precisely define the behaviour of the application during periods of production. Internal factors may be associated with the availability of hardware resources of the company. In this context, Filho [1] treated a stochastic scheduling problem in terms of production under the constraints of the inventory.

Establishing an optimal production planning and maintenance strategy has always been the greatest challenge for industrial companies. Moreover, during the last few decades, the integration of production and maintenance policies problem has received much research attention. In this context, Nodem et al. [2] developed a method to find the optimal production, replacement/repair and preventive maintenance policies for a degraded manufacturing system. Gharbi et al. [3] assumed that failure frequencies can be reduced through preventive maintenance, and developed joint production and preventive maintenance policies depending on produced part inventory levels. An analytical model and a numerical procedure which allow determining a joint optimal inventory control and an age based on preventive maintenance policy for a randomly failing production system was presented by Rezg et al. [4].

This work examined a problem of the optimal production planning formulation of a manufacturing system consisting of one machine producing several products in order to 
meet several random demands. This type of problem was studied by Kenne et al. [5]. They presented an analysis of production control and corrective maintenance problem in a multiple-machine, multiple-product manufacturing system. They obtained a near optimal control policy of the system through numerical techniques by controlling both production and repair rates. Feng et al. [6] developed a multiproduct manufacturing systems problem with sequence dependent setup times and finite buffers under seven scheduling policies. Sloan and Shanthikumar [7] presented a Markov decision process model that simultaneously determines maintenance and production schedules for a multiple-product, singlemachine production system, accounting for the fact that equipment condition can affect the yield of different product types differently. Filho [8] developed a stochastic dynamic optimization model to solve a multiproduct, multiperiod production planning problem with constraints on decision variables and finite planning horizon.

Looking at the literature on integrated maintenance policies, we noticed that the influence of the production rate on the degradation system over a finite planning horizon was rarely addressed in depth. Recently, Zied et al. [9-11] took into account the influence of production plan on the equipment degradation, in the case of a system composed of single machine producing one type of product under randomly failing and satisfying a random demand over a finite horizon. In the same context, Kenne and Nkeungoue [12] proposed a model, where the failure rate of a machine depends on its age; hence, the corrective and preventive maintenance policies are machine-age dependent.

Motivated by the work in the Zied et al. [9-11], we treat the production and maintenance problem in another context that we consider a more complex and real industrial system, composed of one machine that produces several products during a finite horizon divided into subperiods. This study displays that it has a novelty and originality relative to this type of problem which considers the influence of several products on the degradation degree of the considered machine and consequently on the average number of failure as well as on the maintenance strategy.

This paper is organized as follows: Section 2 states the problem. Section 3 presents the notations. The production and maintenance models are developed, respectively, in Sections 4 and 5. A numerical example and sensitivity study are presented, respectively, in Sections 6 and 7. Finally, the conclusion is included in Section 8.

\section{Statement of the Industrial Problem}

This study treated an industrial case. The problem concerns a textile company located in North Africa specialized in clothing manufacturing. The company's production system consists of a conversion of three types of fiber into yarn, then fabric, and textiles. These are then fabricated into clothes or other artefacts. The production machine is called the loom, and it uses a jet of air or water to insert the weft. The loom ensures pattern diversity and faultless fabrics by a flexible and gentle material handling process. Fabrics can be in one

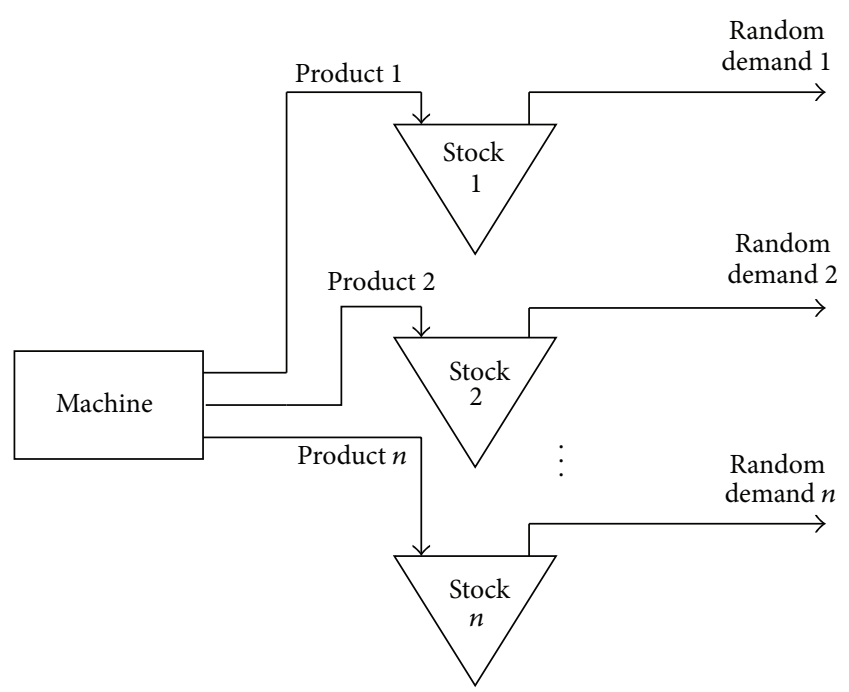

Figure 1: Problem description.

plain color with or without a simple pattern or they can have decorative designs.

Based on the industrial example described, this study was conducted to deal with the problem of an optimal production and maintenance planning for a manufacturing system. The system is composed of a single machine which produces several products in order to meet corresponding several random demands. The problem is presented in (Figure 1).

The considered equipment is subject to random failures. The degradation of the equipment increases with time and varies according to the production rate. The machine is submitted to a preventive maintenance policy in order to reduce the occurrence of failures. In the literature, the influence of the production rate on the material degradation is rarely studied. In this study, this influence was taken into consideration in order to establish the optimal maintenance strategy.

The model developed in this study is based on the works of Zied et al. [9-11]. These studies seek to determine an economical production plan followed by an optimal maintenance policy but for the case of only one product.

Firstly, for a randomly given demand, an optimal production plan was established to minimize the average total storage and production costs while satisfying a service level. Secondly, using the obtained optimal production plan and considering its influence on the manufacturing system failure rate, an optimal maintenance schedule is established to minimize the total maintenance cost.

\section{Notations}

In this paper, we shall as far as possible use the notation summarized as follows:

$\mathrm{Cp}(i)$ : unit production cost of product $i$,

$\mathrm{Cs}(i)$ : holding cost of one unit of product $i$ during $\Delta t$,

St $(i)$ : setup cost of product $i$,

Mc: corrective maintenance action cost, 
Mp: preventive maintenance action cost,

$H$ : total number of periods,

$n$ : total number of products,

$p$ : total number of subperiods during each period,

$\Delta t$ : production period duration,

$U_{i \text { nom }}$ : nominal production quantity of product $i$ during $\Delta t$,

$\theta_{i}$ : probabilistic index (related to customer satisfaction) of product $i$,

$d_{i}(k)$ : demand of product $i$ during period $k$,

$S_{i,(k \times p)-(p-j)}$ inventory level of product $i$ at the end of subperiod $j$ of period $k$,

$Z(U)$ : the total expected cost of production and inventory over the finite horizon,

$\operatorname{Var}\left(d_{i}(k)\right)$ : the demand variance of product $i$ at period $k$,

$\varphi\left(\theta_{i}\right)$ : cumulative Gaussian distribution function,

$\varphi^{-1}\left(\theta_{i}\right)$ : inverse distribution function,

$\Gamma(N)$ : the total cost of maintenance,

$\lambda_{(k \times p)-(p-j)}(\cdot)$ : failure rate function at subperiod $j$ of the period $k$,

$\lambda_{n}(\cdot)$ : nominal failure rate,

$\phi(\cdot)$ : the average number of failures,

$T$ : intervention period for preventive maintenance actions.

\section{Decision Variables}

$U_{i, j, k}$ : production quantity of product $i$ during subperiod $j$ of period $k$,

$\delta_{(k \times p)-(p-j)}$ : duration of subperiod $j$ at period $k$,

$y_{i, j, k}:$ a binary variable, which is equal to 1 if product $i$ is produced in subperiod $j$ of the period $k$, and 0 otherwise,

$N$ : number of preventive maintenance actions during the finite horizon.

\section{Production Policy}

In this section, we developed an analytical model which minimizes the total cost of production and storage. The decision variables are the production quantities $U_{i, j, k}$, the binary variable $y_{i, j, k}$, and the duration of subperiods $\delta_{(k \times p)-(p-j)}$. Our objective consists in determining an economical production plan $U^{*}\left(U^{*}=U_{i, j, k}^{*}, y_{i, j, k}^{*}\right.$ and $\delta_{(k \times p)-(p-j)}^{*} \forall\{i=$ $1, \ldots, n\},\{j=1, \ldots, p\},\{k=1, \ldots, H\})$ for a finite time horizon $H \times \Delta t$. The production plan must satisfy random demands under the requirement of a given level of service, while minimizing the cost of production and storage. The production of each product $i$ will take place at the beginning of subperiods, and delivery to the customer will be at the end of periods.

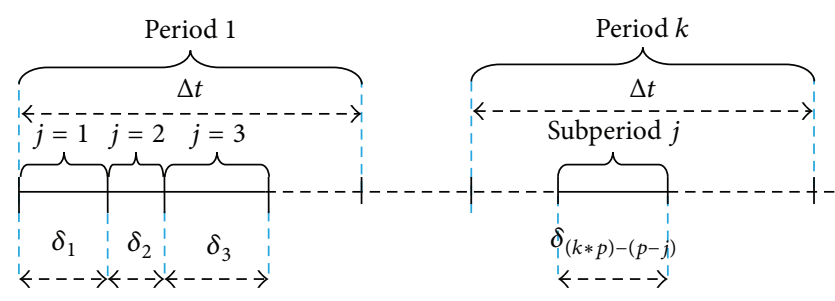

Figure 2: Production plan.

The state of the stock is determined at the end of each subperiod. Figure 2 shows an example of a production plan.

4.1. Stochastic Model of the Problem. To develop this section, the following assumptions are specifically made:

(i) holding and production costs of each product are known and constant;

(ii) only a single product can be produced in each subperiod;

(iii) as described in (Figure 2), we have divided the period $k$ into $p$ equal subperiods, with $p=n$ (the total number of products);

(iv) the standard deviation of demand $\sigma\left(d_{i}\right)$ and the average demand $\widehat{d}_{i}$ for each product and each period $k$ are known and constant.

The model has the following basic structure:

To Minimize $[($ production cost $)+($ Holding cost $)]$

under the constraints below:

(i) the inventory balance equation,

(ii) the service level,

(iii) the admissibility of production plan,

(iv) the maximum production capacity.

Formally

(i) The Cost Functions. Consider

Production cost

$$
=\sum_{k=1}^{H} \sum_{j=1}^{p} \sum_{i=1}^{n} y_{i, j, k} \times\left(\mathrm{St}(i)+\mathrm{Cp}(i) \times U_{i, j, k}\right) .
$$

Holding cost

$$
=\sum_{k=1}^{H} \sum_{j=1}^{p} \sum_{i=1}^{n} \operatorname{Cs}(i) \times \frac{\delta_{(k \times p)-(p-j)}}{\Delta t} \times S_{i,(k \times p)-(p-j)} .
$$

(ii) The Inventory Balance Equation. The available stock at the end of each subperiod $j$ of period $k$ for each product $i$ is 
formulated in the form of flow balance constraints (inflow = outflow):

$$
\begin{aligned}
& S_{i,(k \times p)-(p-j)}= S_{i,(k \times p)-(p-j)-1}+\left(y_{i, j, k} \times U_{i, j, k}\right) \\
&-\operatorname{Int}\left[\frac{j}{p}\right] \times d_{i}(k) \\
& \forall\{i=1, \ldots, n\},\{j=1, \ldots, p\},\{k=1, \ldots, H\},
\end{aligned}
$$

where $S_{i, 0}$ is the initial stock level of product $i$.

This equation shows that the stock of product $i$ at the end of each subperiod $j$ of each period $k((k \times p)-(p-j))$ is determined by the state of the stock of product $i$ at the end of the subperiod $(k \times p)-(p-j)-1$.

(iii) The Admissibility of Production Plan and Service Level Constraints. The service level of product $i$ is determined by the probability constraint on the stock level at the end of each period $k$ :

$$
\operatorname{Prob}\left(S_{i,(k \times p)} \geq 0\right) \geq \theta_{i} \quad \forall\{k=1, \ldots, H\},\{i=1, \ldots, n\} .
$$

We can transform the probabilistic constraint of stock level to a deterministic constraint.

Formally, the function becomes

$$
\begin{array}{r}
\sum_{s=1}^{k} D(i, s)+\text { Stock_min }(i, k) \\
\leq \sum_{s=1}^{k} \sum_{j=1}^{p}\left(y_{(i, j, s)} \times U_{i, j, s}\right)+\text { stock_init }(i, s=0) \\
\forall\{i=1, \ldots, n\},
\end{array}
$$

where $D(i, s)$ is the estimated demand of product $i$ during the period $s, \operatorname{Stock} \min (i, k)$ is the minimum stock level of product $i$ required at the end of period $k$, and $\operatorname{stock}$ init $(i, s=0)$ is the initial stock level of product $i$.

(iv) The Maximum Production Capacity. The production quantity of the machine for each product $i,\{i=1, \ldots, n\}$, is limited and is presented as follows:

$$
\begin{gathered}
0 \leq U_{i, j, k} \leq \frac{\delta_{(k \times p)-(p-j)}}{\Delta t} \times U_{i \text { nom }} \\
\forall\{i=1, \ldots, n\},\{j=1, \ldots, p\},\{k=1, \ldots, H\} .
\end{gathered}
$$

The term $\left\langle\left\langle\delta_{(k \times p)-(p-j)} / \Delta t\right\rangle\right\rangle$ allows taking into account the influence of duration of subperiods $\delta_{(k \times p)-(p-j)}$ on the maximum quantity of production. If $\delta_{(k \times p)-(p-j)}$ tends to 0 , the maximum quantity of production tends also to 0 , and if $\delta_{(k \times p)-(p-j)}$ tends to $\Delta t$, the maximum quantity of production tends to $U_{i \text { nom }}$ (with $U_{i \text { nom }}$ Nominal production quantity of product $i$ during $\Delta t$ ).

However, the term $\left\langle\left\langle\left(\delta t_{(k \times p)-(p-j)} / \Delta t\right) \times U_{i \text { nom }}\right\rangle\right\rangle$ represents the maximum production quantity of product $i$ during the subperiod $j$ of period $k$.
4.2. Problem Formulation. We recall that, in this study, we assume that the horizon is divided into $H$ equal periods and each period is divided into $p$ subperiods with different durations. Figure 2 shows the distribution of the production plan for the finite horizon $H \times \Delta t$. Each product $i$ is produced in a single subperiod $j$ in each period $k$. The demand of each product $i$ is satisfied at the end of each period $k$.

The mathematical formulation of the proposed problem is based on the extension of the model described by Zied et al. [11] for the one product case study.

Their problem is defined as follows:

$$
\begin{aligned}
\operatorname{Min}\left[\operatorname{Cs} \times E\left[S(H)^{2}\right]\right. \\
\left.\quad+\sum_{k=0}^{H-1}\left(\operatorname{Cs} \times E\left[S(k)^{2}\right]+\mathrm{Cp} \times E\left[u(k)^{2}\right]\right)\right],
\end{aligned}
$$

where Cp is unit production cost and Cs is holding cost of a product unit during the period $k$.

Formally, our stochastic production problem is defined as follows:

$$
\begin{gathered}
\operatorname{Min}(\mathrm{Z}(U)) \\
U=U_{i, j, k} \quad \forall\{i=1, \ldots, n\},\{j=1, \ldots, p\},\{k=1, \ldots, H\}
\end{gathered}
$$

with

$$
\begin{aligned}
& Z(U) \\
& =\sum_{k=1}^{H} \sum_{j=1}^{p} \sum_{i=1}^{n}\left[y_{i, j, k} \times\left(\operatorname{St}(i)+\left(\operatorname{Cp}(i) \times E\left[\left(U_{i, j, k}\right)^{2}\right]\right)\right)\right. \\
& +\left(\operatorname{Cs}(i) \times \frac{\delta_{(k \times p)-(p-j)}}{\Delta t}\right. \\
& \left.\left.\times E\left[\left(S_{i,(k \times p)-(p-j)}\right)^{2}\right]\right)\right],
\end{aligned}
$$

where $E[\cdot]$ is the mathematical expectation.

Under the following constraints:

$$
\begin{gathered}
S_{i,(k \times p)-(p-j)}=S_{i,(k \times p)-(p-j)-1}+\left(y_{i, j, k} \times U_{i, j, k}\right) \\
-\operatorname{Int}\left[\frac{j}{p}\right] \times d_{i}(k) \\
\forall\{i=1, \ldots, n\},\{j=1, \ldots, p\},\{k=1, \ldots, H\}, \\
\operatorname{Prob}\left(S_{i,(k \times p)} \geq 0\right) \geq \theta_{i} \quad \forall\{i=1, \ldots, n\},\{k=1, \ldots, H\} \\
\quad 0 \leq U_{i, j, k} \leq \frac{\delta_{(k \times p)-(p-j)}}{\Delta t} \times U_{i \text { nom }} \\
\forall\{i=1, \ldots, n\},\{j=1, \ldots, p\},\{k=1, \ldots, H\}, \\
\sum_{j=1}^{p} \delta_{(k \times p)-(p-j)}=\Delta t \quad \forall\{k=1, \ldots, H\} .
\end{gathered}
$$


The first constraint stands for the inventory balance equation for each product $i,\{i=1, \ldots, n\}$ during each subperiod $j$, $\{j=1, \ldots, p\}$, of period $k,\{k=1, \ldots, H\}$. Equation (11) refers to the satisfaction level of demand of product $i$ in each period $k$. Constraint (12) defines the upper production quantity of the machine for each product $i$. The aim of (13) is to divide each period $k$ into $p$ different subperiods.

The constraints below should also be taken into account:

$$
\begin{gathered}
\sum_{i=1}^{n} y_{i, j, k}=1 \quad \forall\{j=1, \ldots, p\} \text { for }\{k=1, \ldots, H\}, \\
\sum_{j=1}^{p} y_{i, j, k}=1 \quad \forall\{i=1, \ldots, n\} \text { for }\{k=1, \ldots, H\}, \\
y_{i, j, k} \in\{0,1\} \quad \forall\{i=1, \ldots, n\},\{j=1, \ldots, p\},\{k=1, \ldots, H\} .
\end{gathered}
$$

Equation (14) indicates that only one type of product will be produced in subperiod $j$ of period $k$. Constraint (15) states that $y_{i, j, k}$ is a binary variable. We note that $y_{i, j, k}$ is equal to 1 if product $i$ is produced in subperiod $j$ of the period $k$, and 0 otherwise.

For each subperiod $j$ of period $k$, the equation of the stock status is determined by the first constraint. This equation remains random because of the uncertainty of fluctuating demand. Therefore, the variables of production and storage are stochastic. Their statistics depend on a probabilistic distribution function of demand. It is, therefore, necessary to use constraint (11) for decision variables. These constraints can help us to analyse the various production scenarios to improve the performance of the production system.

4.3. The Deterministic Production Model. We admit that a function $f_{(i, j, k)} \forall\{i=1, \ldots, n\},\{j=1, \ldots, p\},\{k=1, \ldots, H\}$, represents the cost of storage and production which is relative to the proposed plan and $E[\cdot]$ represents the value of the mathematical expectation. The quantity stocked of product $i$ at the end of the subperiod $j$ of period $k$ is stood for by $S_{i,(k \times p)-(p-j)}$. The production quantity required to satisfy the demand of product $i$ at the end of period $k$ is $U_{i, j, k}$, where $j$ represents the subperiod during which the product $i$ is produced.

Thus, the problem formulation can be presented as follows:

$$
U^{*}=\operatorname{Min}\left[E\left[f_{(i, j, k)}\left(U_{i, j, k}, S_{i,(k \times p)-(p-j)}\right)\right]\right] .
$$

The purpose, then, is to determine the decision variables $\left(U_{i, j, k}, y_{i, j, k}\right.$ and $\left.\delta_{(k \times p)-(p-j)}\right)$ required to satisfy economically the various demands under the constraints seen in the previous subsection.
The resolution of the stochastic problem under these assumptions is generally difficult. Thus, its transformation into a deterministic problem facilitates its resolution.

(i) Inventory Balance Equation. The stochastic inventory balance equation is

$$
\begin{aligned}
& S_{i,(k \times p)-(p-j)}= S_{i,(k \times p)-(p-j)-1}+\left(y_{i, j, k} \times U_{i, j, k}\right) \\
&-\operatorname{Int}\left[\frac{j}{p}\right] \times d_{i}(k), \\
& \forall\{i=1, \ldots, n\},\{j=1, \ldots, p\},\{k=1, \ldots, H\}
\end{aligned}
$$

with $S_{i, 0}$ being the initial stock level of product $i$.

We suppose that the means and variance of demand are known and constant for each product $i$ in each period $k$.

Therefore,

$$
\begin{gathered}
E\left[d_{i}(k)\right]=\widehat{d}_{i}(k), \quad \operatorname{Var}\left[d_{i}(k)\right]=\sigma^{2}\left(d_{i}(k)\right) \\
\forall\{i=1, \ldots, n\},\{k=1, \ldots, H\} .
\end{gathered}
$$

The inventory equation $S_{i,(k \times p)-(p-j)}$ is statistically described by its means:

$$
\begin{array}{r}
E\left[S_{i,(k \times p)-(p-j)}\right]=\widehat{S}_{i,(k \times p)-(p-j)} \\
\forall\{i=1, \ldots, n\},\{j=1, \ldots, p\},\{k=1, \ldots, H\} .
\end{array}
$$

We note that

$$
E\left[U_{i, j, k}\right]=\widehat{U}_{i, j, k}=U_{i, j, k}
$$

because $U_{i, j, k}$ is constant for each interval $\delta_{(k \times p)-(p-j)}$.

And

$$
\begin{gathered}
\operatorname{Var}\left(U_{i, j, k}\right)=0 \\
\forall\{i=1, \ldots, n\},\{j=1, \ldots, p\},\{k=1, \ldots, H\} .
\end{gathered}
$$

Then, the balance equation (10) can be converted into an equivalent inventory balance equation:

$$
\begin{aligned}
& \widehat{S}_{i,(k \times p)-(p-j)}= \widehat{S}_{i,(k \times p)-(p-j)-1}+\left(y_{i, j, k} \times U_{i, j, k}\right) \\
&-\operatorname{Int}\left[\frac{j}{p}\right] \times \widehat{d}_{i}(k) \\
& \forall\{i=1, \ldots, n\},\{j=1, \ldots, p\},\{k=1, \ldots, H\},
\end{aligned}
$$

with $\widehat{S}_{i, 0}$ being the average initial stock level of product.

(ii) Service Level Constraint. The second step is to convert the service level constraint into a deterministic equivalent constraint by specifying certain minimum cumulative production quantities that depend on the service level requirements.

Lemma 1. Consider the following:

$$
\begin{array}{r}
\sum_{j=1}^{p}\left(y_{i, j, k} \times U_{i, j, k}\right) \geq \operatorname{Var}\left(d_{i}(k)\right) \times \varphi^{-1}\left(\theta_{i}\right)+\widehat{d}_{i}(k)-S_{i,(k-1) \times p} \\
\forall\{i=1, \ldots, n\},\{k=1, \ldots, H\} .
\end{array}
$$


Proof. We know that

$$
\operatorname{Prob}\left(S_{i,(k \times p)} \geq 0\right) \geq \theta_{i} \quad \forall\{i=1, \ldots, n\},\{k=1, \ldots, H\},
$$

$$
\begin{gathered}
S_{i,(k \times p)}=S_{i,(k-1) \times p}+\sum_{j=1}^{p}\left(y_{i, j, k} \times U_{i, j, k}\right)-d_{i}(k) \\
\forall\{i=1, \ldots, n\},\{k=1, \ldots, H\} \\
\Longrightarrow \operatorname{Prob}\left(S_{i,(k-1) \times p}\right. \\
\left.+\sum_{j=1}^{p}\left(y_{i, j, k} \times U_{i, j, k}\right)-d_{i}(k) \geq 0\right) \geq \theta_{i} \\
\forall\{i=1, \ldots, n\},\{k=1, \ldots, H\}
\end{gathered}
$$$$
\Longrightarrow \operatorname{Prob}\left(S_{i,(k-1) \times p}\right.
$$$$
\left.+\sum_{j=1}^{p}\left(y_{i, j, k} \times U_{i, j, k}\right) \geq d_{i}(k)\right) \geq \theta_{i}
$$$$
\forall\{i=1, \ldots, n\},\{k=1, \ldots, H\}
$$$$
\Longrightarrow \operatorname{Prob}\left(S_{i,(k-1) \times p}+\sum_{j=1}^{p}\left(y_{i, j, k} \times U_{i, j, k}\right)-\widehat{d}_{i}(k)\right.
$$$$
\left.\geq d_{i}(k)-\widehat{d}_{i}(k)\right) \geq \theta_{i}
$$$$
\forall\{i=1, \ldots, n\},\{k=1, \ldots, H\}
$$$$
\Longrightarrow \operatorname{Prob}\left(\frac{S_{i,(k-1) \times p}+\sum_{j=1}^{p}\left(y_{i, j, k} \times U_{i, j, k}\right)-\widehat{d}_{i}(k)}{\operatorname{Var}\left(d_{i}(k)\right)}\right.
$$$$
\left.\geq \frac{d_{i}(k)-\widehat{d}_{i}(k)}{\operatorname{Var}\left(d_{i}(k)\right)}\right) \geq \theta_{i}
$$

$$
\forall\{i=1, \ldots, n\},\{k=1, \ldots, H\} .
$$

Noting that

$$
X=\frac{d_{i}(k)-\widehat{d}_{i}(k)}{\operatorname{Var}\left(d_{i}(k)\right)}
$$

$X$ is a Gaussian random variable for demand $d_{i}(k)$.

Hence,

$$
\begin{array}{r}
\operatorname{Prob}\left(\frac{S_{i,(k-1) \times p}+\sum_{j=1}^{p}\left(y_{i, j, k} \times U_{i, j, k}\right)-\widehat{d}_{i}(k)}{\operatorname{Var}\left(d_{i}(k)\right)} \geq X\right) \geq \theta_{i} \\
\forall\{i=1, \ldots, n\},\{k=1, \ldots, H\} .
\end{array}
$$

We recall that $\theta_{i}$ represents the probabilistic index (related to customer satisfaction) of product $i$ and $\operatorname{Var}\left(d_{i}(k)\right)$ represents the demand variance of product $i$ at period $k$.

The distribution function is invertible because it is an increasing and differentiable function.

Hence,

$$
\begin{array}{r}
S_{i,(k-1) \times p}+\sum_{j=1}^{p}\left(y_{i, j, k} \times U_{i, j, k}\right)-\widehat{d}_{i}(k) \geq \operatorname{Var}\left(d_{i}(k)\right) \times \varphi^{-1}\left(\theta_{i}\right) \\
\forall\{i=1, \ldots, n\},\{k=1, \ldots, H\} .
\end{array}
$$

Therefore,

$$
\begin{array}{r}
\sum_{j=1}^{p}\left(y_{i, j, k} \times U_{i, j, k}\right) \geq \operatorname{Var}\left(d_{i}(k)\right) \times \varphi^{-1}\left(\theta_{i}\right)+\widehat{d}_{i}(k)-S_{i,(k-1) \times p} \\
\forall\{i=1, \ldots, n\},\{k=1, \ldots, H\} .
\end{array}
$$

(iii) The Expression of the Total Production and Storage Cost. In this step, we proceed to a simplification of the expected cost of production and storage.

The expression of the total cost of production is presented as follows.

Lemma 2. Consider the following:

$$
\begin{aligned}
& Z(U)=\sum_{k=1}^{H} \sum_{j=1}^{P} \sum_{i=1}^{n}\left\{y_{i, j, k} \times\left(\operatorname{St}(i)+\left(\operatorname{Cp}(i) \times U^{2}{ }_{i, j, k}\right)\right)\right. \\
&+ \operatorname{Cs}(i) \times \frac{\delta_{(k \times p)-(p-j)}}{\Delta t} \\
& \times \sigma^{2}\left(S_{i, 0}\right) \\
&+\left(\sum_{Q=1}^{k-1} \sum_{l=1}^{p} \operatorname{Int}\left(\frac{l}{p}\right) \times \sigma^{2}\left(d_{i}(Q)\right)\right) \\
&+\left(\sum_{l=1}^{j} \operatorname{Int}\left(\frac{l}{p}\right) \times \sigma^{2}\left(d_{i}(k)\right)\right) \\
&\left.\left.+\left(\widehat{S}_{i,(k \times p)-(p-j)}\right)^{2}\right]\right\} .
\end{aligned}
$$

Proof. See Appendix A. 
(iv) In Summary. The deterministic optimization problem becomes as follows.

(a) The Objective Function. Consider

$$
\begin{aligned}
U^{*}=\operatorname{Min} \sum_{k=1}^{H} \sum_{j=1}^{P} \sum_{i=1}^{n}[ & y_{i, j, k} \times\left(\operatorname{St}(i)+\left(\operatorname{Cp}(i) \times U^{2}{ }_{i, j, k}\right)\right) \\
+ & \operatorname{Cs}(i) \times \frac{\delta_{(k \times p)-(p-j)}}{\Delta t} \\
\times & {\left[\sigma^{2}\left(S_{i, 0}\right)\right.} \\
& +\left(\sum_{Q=1}^{k-1} \sum_{l=1}^{p} \operatorname{Int}\left(\frac{l}{p}\right) \times \sigma^{2}\left(d_{i}(Q)\right)\right) \\
& +\left(\sum_{l=1}^{j} \operatorname{Int}\left(\frac{l}{p}\right) \times \sigma^{2}\left(d_{i}(k)\right)\right) \\
& \left.\left.+\left(\widehat{S}_{i,(k \times p)-(p-j)}\right)^{2}\right]\right] .
\end{aligned}
$$

(b) The Constraints. Consider

$$
\begin{gathered}
\widehat{S}_{i,(k \times p)-(p-j)}=\widehat{S}_{i,(k \times p)-(p-j)-1}+\left(y_{i, j, k} \times U_{i, j, k}\right) \\
-\operatorname{Int}\left[\frac{j}{p}\right] \times \widehat{d}_{i}(k) \\
\forall\{i=1, \ldots, n\},\{j=1, \ldots, p\},\{k=1, \ldots, H\}, \\
\sum_{j=1}^{p}\left(y_{i, j, k} \times U_{i, j, k}\right) \geq \operatorname{Var}\left(d_{i}(k)\right) \times \varphi^{-1}\left(\theta_{i}\right) \\
\quad+\widehat{d}_{i}(k)-S_{i,(k-1) \times p} \\
\forall\{i=1, \ldots, n\},\{k=1, \ldots, H\}, \\
0 \leq U_{i, j, k} \leq \frac{\delta_{(k \times p)-(p-j)} \times U_{i \text { nom }}}{\Delta t} \\
\forall\{i=1, \ldots, n\},\{j=1, \ldots, p\},\{k=1, \ldots, H\}, \\
\sum_{j=1}^{p} \delta_{(k \times p)-(p-j)}=\Delta t, \quad \forall\{k=1, \ldots, H\} .
\end{gathered}
$$

\section{Maintenance Strategy}

5.1. Description of the Maintenance Strategy. The maintenance strategy adopted in this study is known as preventive maintenance with minimal repair. The actions of preventive maintenance are practiced in the period $q \times T(q=1,2, \ldots)$. The replacement rule for this policy is to replace the system with another new system (as good as new) at each period $q \times$

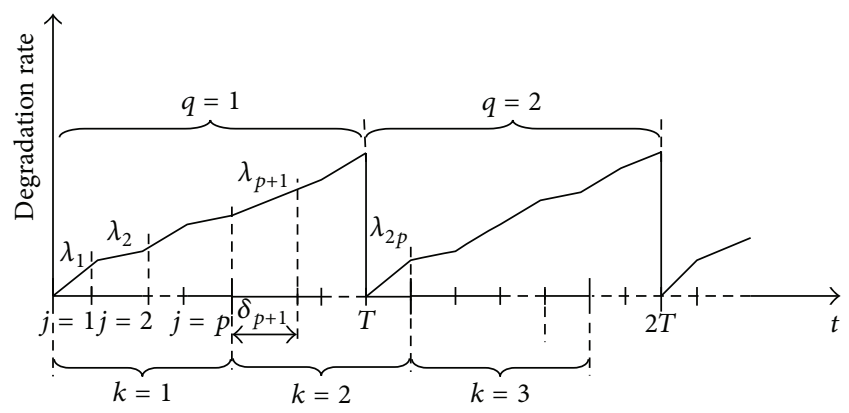

FIgURE 3: Degradation rate.

$T$. At each failure between preventive maintenance actions, only one minimal repair is implemented. If we note $\mathrm{Mc}$, the cost of corrective maintenance actions, and $\mathrm{Mp}$, the cost of preventive maintenance actions and degradation of the machine is linear, the total cost of maintenance is expressed as follows:

$$
\Gamma(N)=\operatorname{Mc} \times \phi_{(N, U)}+\operatorname{Mp} \times N
$$

To develop the analytical model, it was assumed that

(i) durations of maintenance actions are negligible;

(ii) Mp and Mc costs incurred by the preventive and corrective maintenance actions are known and constant, with $\mathrm{Mc} \gg \mathrm{Mp}$;

(iii) preventive maintenance actions are always performed at the end of the subperiods of production.

The aim of this maintenance strategy is to find the optimal number of preventive maintenance actions $N^{*}(N=1,2, \ldots)$ minimizing the total cost of maintenance over a given horizon $H \times \Delta t$. The existence of an optimal number of partitions $N^{*}$ and, therefore, the optimal preventive maintenance period $T^{*}$ is proven in the literature. It has been proven that $T^{*}$ exists if the failure rate is increasing [13].

Before determining the analytical model minimizing the total cost of maintenance, we need first to develop the expression of the failure rate $\lambda_{(k \times p)-(p-j)}(t)$ and then the average number of failures expression $\phi_{(U, N)}$, during the finite horizon $H \times \Delta t$.

5.2. Expression of Failure Rate. Recall that the key of this study is the influence of the variation of the production rates on the failure rate.

Figure 3 represents the general description of the evolution of the failure rate, which depends on both the production rate and the failure rate of the previous period.

As presented in Figure 3, the failure rate is reset after each $q \times T$, with $q=1, \ldots, N+1$. 


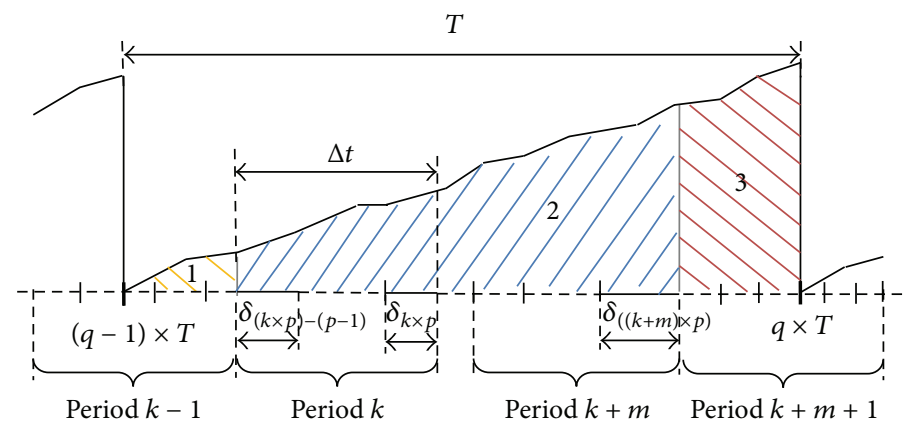

FIgURE 4: The evolution of the failure rate during the interval $[(q-1) \times T, q \times T]$.

Thus, the expression of the failure rate depending on time and production rate can be written as follows:

$$
\begin{aligned}
& \lambda_{(k \times p)-(p-j)}(t) {\left[\left(\lambda_{(k \times p)-(p-j)-1}\left(\delta_{(k \times p)-(p-j)-1}\right)\right)\right.} \\
&=\left(1-\operatorname{In}\left[\frac{(k \times p)-(p-j+1)}{q \times T}\right]\right) \\
&\left.+\sum_{i=1}^{n} \frac{U_{i, j, k}}{\delta_{(k \times p)-(p-j)}} \times \frac{1}{U_{i \mathrm{nom}} / \Delta t} \times \lambda_{n}(t)\right] \\
& \forall t \in\left[0, \delta_{(k \times p)-(p-j)}\right], \quad \forall\{k=1, \ldots, H\},\{j=1, \ldots, p\} .
\end{aligned}
$$

The term $\left\langle\left\langle U_{i, j, k} / \delta_{(k \times p)-(p-j)}\right\rangle\right\rangle$ represents the production rate of product $i$ during subperiod $j$ of period $k$.

The term $\left\langle\left\langle U_{i \text { nom }} / \Delta t\right\rangle\right\rangle$ represents the nominal production rate of product $i$ during $\Delta t$.

Therefore,

$$
\begin{aligned}
& \lambda_{(k \times p)-(p-j)}(t) \\
& =\left[\left(\lambda_{(k \times p)-(p-j)-1}\left(\delta_{(k \times p)-(p-j)-1}\right)\right)\right. \\
& \quad \times\left(1-\operatorname{In}\left[\frac{(k \times p)-(p-j+1)}{q \times T}\right]\right) \\
& \left.\quad+\sum_{i=1}^{n} \frac{U_{i, j, k} \times \Delta t}{U_{i \text { nom }} \times \delta_{(k \times p)-(p-j)}} \times \lambda_{n}(t)\right] \\
& \forall t \in\left[0, \delta_{(k \times p)-(p-j)}\right], \quad \forall\{k=1, \ldots, H\},\{j=1, \ldots, p\} .
\end{aligned}
$$

The aim of the expression $(1-\operatorname{In}[((k \times p)-(p-j)) /(q \times T)])$ is to reset the failure rate after each $q \times T$ with $q=1, \ldots, N+1$.

Note that

$$
q=\operatorname{In}\left[\frac{(k \times p)-(p-j+2)}{T}\right]+1,
$$

where $\operatorname{In}[x]$ is the integer part of number $x$.
Lemma 3. Consider the following:

$$
\begin{aligned}
& \lambda_{(k \times p)-(p-j)}(t) {\left[\left(\lambda_{0}+\sum_{Q=1}^{k-1} \sum_{l=1}^{p} \sum_{i=1}^{n} \frac{U_{i, l, Q} \times \Delta t}{U_{i \max } \times \delta_{(Q \times p)-(p-l)}}\right.\right.} \\
& \times \lambda_{n}\left(\delta_{(Q \times p)-(p-l)}\right) \\
&+\sum_{l=1}^{j-1} \sum_{i=1}^{n} \frac{U_{i, l, k} \times \Delta t}{U_{i \max } \times \delta_{(k \times p)-(p-l)}} \\
&\left.\times \lambda_{n}\left(\delta_{(k \times p)-(p-l)}\right)\right) \\
& \times\left(1-\operatorname{In}\left[\frac{(k \times p)-(p-j+1)}{q \times T}\right]\right) \\
&\left.+\sum_{i=1}^{n} \frac{U_{i, j, k} \times \Delta t}{U_{i \max } \times \delta_{(k \times p)-(p-j)}} \times \lambda_{n}(t)\right] \\
& t \in\left[0, \delta_{(k \times p)-(p-j)}\right], \quad \forall\{k=1, \ldots, H\},\{j=1, \ldots, p\} .
\end{aligned}
$$

Proof. See Appendix B.

5.3. Expression of the Average Number of Failures. In order to reduce the complexity of the generation of the optimal number of preventive maintenance, we assume that interventions are made at the end of subperiods.

Hence, the function of the period of intervention is presented as follows:

$$
T=\operatorname{Round}\left[\frac{H \times p}{N}\right]
$$

where Round $[x]$ is a round number of $x$.

To determine the average number of failures expression $\phi_{(U, N)}$ during the finite horizon $H \times \Delta t$, we will focus on the calculation of the average number of failures during the 
interval $[(q-1) \times T, q \times T]$, which we designate $\phi_{(U, N)}^{T}$. Hence, we have to calculate the three surfaces $\{1\},\{2\}$, and $\{3\}$ mentioned in Figure 4.
Therefore, the average number of failures expression during the interval $[(q-1) \times T, q \times T]$ is presented as follows:

$$
\begin{aligned}
\phi_{(U, N)}^{T}= & {\left[\sum_{j=((q-1) \times T+1)-(\operatorname{In}[((q-1) \times T) / \Delta t] \times p)}^{p} \int_{0}^{\delta_{(\operatorname{In}[((q-1) \times T) / \Delta t]+1) \times p-(p-j)}} \lambda_{(\operatorname{In}[((q-1) \times T) / \Delta t]+1) \times p-(p-j)}(t) d t\right.} \\
& +\sum_{k=\operatorname{In}_{\text {sup }}[((q-1) \times T+1) / \Delta t]+1}^{\operatorname{In}[(q \times T) / \Delta t]} \sum_{j=1}^{\delta_{(k \times p)-(p-j)}} \lambda_{(k \times p)-(p-j)}(t) d t \\
& \left.+\sum_{j \times 1}^{q \times T-\operatorname{In}[(q \times T) / \Delta t] \times p} \int_{0}^{\delta_{(\operatorname{In}[(q \times T) / \Delta t]+1) \times p-(p-j)}} \lambda_{(\operatorname{In}[(q \times T) / \Delta t]+1) \times p-(p-j)}(t) d t\right],
\end{aligned}
$$

where $\operatorname{In}_{\text {sup }}[x]$ is the superior integer part of number $x$.

Thus, the average number of failures expression $\phi_{(U, N)}$ during the finite horizon $H \times \Delta t$ is defined by

$$
\phi_{(U, N)}=\sum_{q=1}^{N+1} \phi_{(U, N)}^{T} .
$$

Therefore, we have the following lemma.

$$
\begin{aligned}
\phi_{(U, N)}=\sum_{q=1}^{N+1}\left[\sum_{j=((q-1) \times T+1)-(\operatorname{In}[((q-1) \times T) / \Delta t] \times p)}^{p} \int_{0}^{\delta_{(\operatorname{In}[(q-1) \times T) / \Delta t]+1) \times p-(p-j)}} \lambda_{(\operatorname{In}[((q-1) \times T) / \Delta t]+1) \times p-(p-j)}(t) d t\right. \\
+\sum_{k=\operatorname{In} \sup [((q-1) \times T+1) / \Delta t]+1} \sum_{j=1}^{p} \int_{0}^{\delta_{(k \times p)-(p-j)}[(q \times T) / \Delta t]} \lambda_{(k \times p)-(p-j)}(t) d t \\
\left.+\sum_{j=1}^{q \times T-\operatorname{In}[(q \times T) / \Delta t] \times p} \int_{0}^{\delta_{(\operatorname{In}[(q \times T) / \Delta t]+1) \times p-(p-j)}} \lambda_{(\operatorname{In}[(q \times T) / \Delta t]+1) \times p-(p-j)}(t) d t\right] .
\end{aligned}
$$

Note that $N=1,2, \ldots$

5.4. Expression of the Total Cost of Maintenance. We recall that the initial expression of the total cost of maintenance presented in (33) is

$$
\Gamma(N)=\mathrm{Mc} \times \phi_{(U, N)}+\mathrm{Mp} \times N .
$$

$$
\begin{aligned}
& \Gamma(N)=\left[\operatorname{Mc} \times \sum_{q=1}^{N+1}\left[\sum_{j=((q-1) \times T+1)-(\operatorname{In}[((q-1) \times T) / \Delta t] \times p)}^{p} \int_{0}^{\delta_{(\operatorname{In}[((q-1) \times T) / \Delta t]+1) \times p-(p-j)}} \lambda_{(\operatorname{In}[((q-1) \times T) / \Delta t]+1) \times p-(p-j)}(t) d t\right.\right. \\
&+\sum_{k=\operatorname{In} \text { sup }}[((q-1) \times T+1) / \Delta t]+1 \\
&+\sum_{j=1}^{\operatorname{In}[(q \times T) / \Delta t]} \int_{0}^{\delta_{(k \times p)-(p-j)}} \lambda_{(k \times p)-(p-j)}(t) d t \\
&\left.\left.\quad \sum_{j=1}^{q \operatorname{In}[(q \times T) / \Delta t] \times p} \int_{0}^{\delta_{(\operatorname{In}[(q \times T) / \Delta t]+1) \times p-(p-j)}} \lambda_{(\operatorname{In}[(q \times T) / \Delta t]+1) \times p-(p-j)}(t) d t\right]+\operatorname{Mp} \times N\right] .
\end{aligned}
$$


The goal is to find the optimal number of preventive maintenance actions $N^{*}$ that minimizes the total cost of maintenance $\Gamma(N)$. Using this decision variable, we can deduce the optimal period of intervention $T^{*}$, knowing that $T^{*}=$ Round $\left[(H \times p) / N^{*}\right]$.

5.5. Existence of an Optimal Solution. The following equation determines analytically the optimal solution:

$$
\frac{\partial \Gamma(N)}{\partial N}=0
$$

Since it is difficult to solve analytically the expression of maintenance cost, we use numerical procedure.

We start by proving the existence of a local minimum.

We have the following.

Limits at the terminals of $\Gamma(N)$ are

$$
\begin{aligned}
\lim _{N \rightarrow 1} \Gamma(U, N) & =\lim _{N \rightarrow 1}(\underbrace{M_{c} \times \phi(U, N)}_{\rightarrow \text { constant }}+\underbrace{M_{p} \times N}_{\rightarrow \text { constant }}) \\
& =M_{c} \times \phi(U, 1)+M_{p}, \\
\lim _{N \rightarrow+\infty} \Gamma(U, N) & =\lim _{N \rightarrow+\infty}(\underbrace{M_{c} \times \phi(U, N)}_{\rightarrow 0}+\underbrace{M_{p} \times N}_{\rightarrow+\infty}) \\
& =+\infty .
\end{aligned}
$$

Note that $\phi(U, N)$ is the average number of failures. Mc and $\mathrm{Mp}$ represent, respectively, the corrective and the preventive maintenance costs.

Moreover,

$$
\begin{aligned}
& \Gamma(U, N+1)-\Gamma(U, N) \geq 0 \\
& \Longrightarrow\left[M_{c} \times \phi(U,(N+1))+M_{p} \times(N+1)\right] \\
& \quad-\left[M_{c} \times \phi(U, N)+M_{p} \times N\right] \geq 0 \\
& \Longrightarrow M_{c} \times(\phi(U,(N+1))-\phi(U, N))+M_{p} \geq 0 \\
& \Longrightarrow \phi(U,(N+1))-\phi(U, N) \leq \frac{M_{p}}{M_{c}} .
\end{aligned}
$$

In addition,

$$
\begin{aligned}
& \Gamma(U, N)-\Gamma(U, N-1) \leq 0 \\
& \Longrightarrow\left[M_{c} \times \phi(U, N)+M_{p} \times(N)\right] \\
& \quad-\left[M_{c} \times \phi(U,(N-1))+M_{p} \times(N-1)\right] \leq 0 \\
& \Longrightarrow M_{c} \times(\phi(U, N)-\phi(U,(N-1)))-M_{p} \leq 0 \\
& \Longrightarrow \phi(U, N)-\phi(U,(N-1)) \geq \frac{M_{p}}{M_{c}} .
\end{aligned}
$$

In summary, there is an optimal number of partition $N^{*}$, which is unique and satisfies the previous relations (46) and (47). The following lemma ensures the existence of a local minimum.
Lemma 5. Consider the following:

$$
\exists N^{*} \text { si } \quad \xi_{N} \leq \frac{M_{p}}{M_{c}} \leq \xi_{N-1},
$$

with

$$
\xi_{N}=\phi(U, N)-\phi(U,(N+1)) .
$$

Therefore, there exists an optimal number of partition $N^{*}$, which satisfies the following expressions:

$$
N^{*} \exists s i\left\{\begin{array}{l}
\phi(U,(N+1))-\phi(U, N) \geq 0 \\
\phi(U, N)-\phi(U,(N-1)) \leq 0 \\
\lim _{N \rightarrow 1} \Gamma(U, N)=\text { Constant } \\
\lim _{N \rightarrow+\infty} \Gamma(U, N)=+\infty .
\end{array}\right.
$$

The resolution of this maintenance policy, using a numerical procedure, is performed by incrementing the number of maintenance intervals until an $N^{*}$, satisfying the two first relations in Lemma 5 and minimizing the total cost of maintenance $\Gamma(N)$ described by (43).

\section{Numerical Example}

From the industrial example presented in Section 2, we have considered a system producing 3 types of fiber in order to meet three random demands according to every type of product. Using the analytical models developed in previous sections, we start by establishing the optimal production plan and then we determine the optimal maintenance strategy expressed as optimal number of preventive maintenance minimizing the total cost of maintenance over a finite planning horizon: $H=8$ trimesters (two years). We note that the optimal maintenance strategy is obtained while considering of the influence of the production plan on the system degradation. We supposed that the standard deviation of demand of product $i$ is the same for all periods. The data required to run this model are given in sequence.

\subsection{Numerical Example}

(i) The Data Relating to Production. The mean demands (in bobbins) as shown in Table 1:

$$
\begin{aligned}
& \widehat{d}_{1}=200, \quad \sigma\left(d_{1}\right)=1.5, \\
& \widehat{d}_{2}=110, \quad \sigma\left(d_{2}\right)=0.9, \\
& \widehat{d}_{3}=320, \quad \sigma\left(d_{3}\right)=1.2 .
\end{aligned}
$$

The other data are presented as shown in Table 2.

(ii) The Data Relating to System Reliability. System reliability and costs related to maintenance actions are defined by the following data:

(1) the law of failure characterizing the nominal conditions is Weibull. It is defined by 
TABLE 1

\begin{tabular}{lcccccccc}
\hline & & & \multicolumn{3}{c}{ Demands } & \multicolumn{1}{c}{ Trim. 6 } & Trim. 7 & Trim. 8 \\
\hline Product 1 & Trim. 1 & Trim. 2 & Trim. 3 & Trim. 4 & Trim. & Trim. & 200 & 199 \\
Product 2 & 111 & 199 & 198 & 199 & 201 & 112 & 110 & 110 \\
Product 3 & 321 & 119 & 108 & 111 & 321 & 317 & 320 \\
\hline
\end{tabular}

TABLE 2

\begin{tabular}{lccccc}
\hline & $\begin{array}{c}\text { Initial stock level } \\
S_{i, 0}(\text { up })\end{array}$ & $\begin{array}{c}\text { Nominal production quantities } \\
U_{i \text { nom }}(\text { up })\end{array}$ & $\begin{array}{c}\text { Unit production costs } \\
\mathrm{Cp}(i)(\mathrm{um})\end{array}$ & $\begin{array}{c}\text { Unit holding costs } \\
\mathrm{Cs}(i)(\mathrm{um} / \mathrm{ut})\end{array}$ & $\begin{array}{c}\text { Satisfaction rates } \\
\theta_{i}(\%)\end{array}$ \\
\hline Product 1 & 110 & 750 & 13 & 3 & 87 \\
Product 2 & 85 & 530 & 17 & 5 & 95 \\
Product 3 & 145 & 1150 & 9 & 2 & 90 \\
\hline
\end{tabular}

TABLE 3: The optimal production plan.

\begin{tabular}{|c|c|c|c|c|c|c|c|c|c|c|c|c|}
\hline & \multicolumn{3}{|c|}{ Trimester 1} & \multicolumn{3}{|c|}{ Trimester 2} & \multicolumn{3}{|c|}{ Trimester 3} & \multicolumn{3}{|c|}{ Trimester 4} \\
\hline & $\delta_{1}$ & $\delta_{2}$ & $\delta_{3}$ & $\delta_{4}$ & $\delta_{5}$ & $\delta_{6}$ & $\delta_{7}$ & $\delta_{8}$ & $\delta_{9}$ & $\delta_{10}$ & $\delta_{11}$ & $\delta_{12}$ \\
\hline & 0.85 & 0.71 & 1.44 & 1.19 & 1.20 & 0.61 & 0.81 & 1.18 & 1.01 & 0.43 & 0.74 & 1.83 \\
\hline Product 1 & 0 & 169 & 0 & 388 & 0 & 0 & 0 & 321 & 0 & 0 & 151 & 0 \\
\hline Product 2 & 150 & 0 & 0 & 0 & 185 & 0 & 134 & 0 & 0 & 0 & 0 & 312 \\
\hline \multirow[t]{4}{*}{ Product 3} & 0 & 0 & 507 & 0 & 0 & 230 & 0 & 0 & 387 & 158 & 0 & 0 \\
\hline & \multicolumn{3}{|c|}{ Trimester 5} & \multicolumn{3}{|c|}{ Trimester 6} & \multicolumn{3}{|c|}{ Trimester 7} & \multicolumn{3}{|c|}{ Trimester 8} \\
\hline & $\delta_{13}$ & $\delta_{14}$ & $\delta_{15}$ & $\delta_{16}$ & $\delta_{17}$ & $\delta_{18}$ & $\delta_{19}$ & $\delta_{20}$ & $\delta_{21}$ & $\delta_{22}$ & $\delta_{23}$ & $\delta_{24}$ \\
\hline & 1.82 & 0.87 & 0.31 & 0.56 & 0.55 & 1.89 & 1.36 & 0.51 & 1.13 & 1.05 & 0.77 & 1.18 \\
\hline Product 1 & 0 & 212 & 0 & 0 & 138 & 0 & 272 & 0 & 0 & 130 & 0 & 0 \\
\hline Product 2 & 0 & 0 & 52 & 58 & 0 & 0 & 0 & 0 & 92 & 0 & 81 & 0 \\
\hline Product 3 & 554 & 0 & 0 & 0 & 0 & 422 & 0 & 202 & 0 & 0 & 0 & 135 \\
\hline
\end{tabular}

(a) scale parameter $(\beta)$ : 12 months,

(b) shape parameter $(\alpha): 2$,

(c) position parameter $(\gamma)$ : 0 ,

(2) the initial failure rate: $\lambda_{0}=0$.

These parameters provide information on the evolution of the failure rate in time.

This failure rate is increasing and linear over time. Thus, the function of the nominal failure rate is expressed by

$$
\lambda_{n}(t)=\frac{\alpha}{\beta} \times\left(\frac{t}{\beta}\right)^{\alpha-1}=\frac{2}{12} \times\left(\frac{t}{12}\right) .
$$

The preventive and corrective maintenance costs are, respectively, $\mathrm{Mp}=800 \mathrm{mu}$ and $\mathrm{Mc}=1500 \mathrm{mu}$.

6.2. Determination of the Economic Production Plan. The economic production plan obtained is presented in Table 3.

6.3. Determination of the Optimal Maintenance Plan. As described in Figure 5, the optimal maintenance strategy is obtained based on the optimal production plan given in the previous section.

Figure 6 shows the curve of the total cost of maintenance according to $N$ (number of preventive maintenance actions).
We conclude that the optimal number of preventive maintenance actions that minimizes the total cost of maintenance during the finite horizon (two years) is $N^{*}=2$ times. Hence, the optimal period to intervene for the preventive maintenance is $T^{*}=12$ months, and the minimal total cost of maintenance $\Gamma^{*}(N)=3316 \mathrm{mu}$.

\section{The Economical Profit of the Study}

We recall that the specificity of this study is that it considered the impact of the production rate variation on the system degradation and consequently on the optimal maintenance strategy adopted in the case of multiple product. In order to show the significance of our study we will consider, in this section, the case of not considering the influence of the production rate variation on the system's degradation. That is to say, we assume that the manufacturing system is exploited at its maximal production rate every time. Analytically, we will consider the nominal failure rate which depends only on time. The results of this study are presented in Table 4 .

The optimal number of preventive maintenance obtained in the case when we did not consider the variation of production rate is $N^{*}=3$ times and it corresponds to a total cost of maintenance during the finite horizon (two years), $\Gamma^{*}(N)=$ $3704 \mathrm{mu}$. We recall that in our case study when we consider 


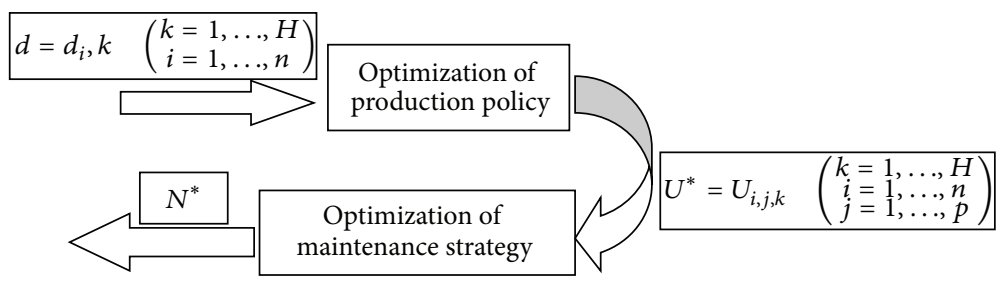

FIGURE 5: Sequential production and maintenance optimization.

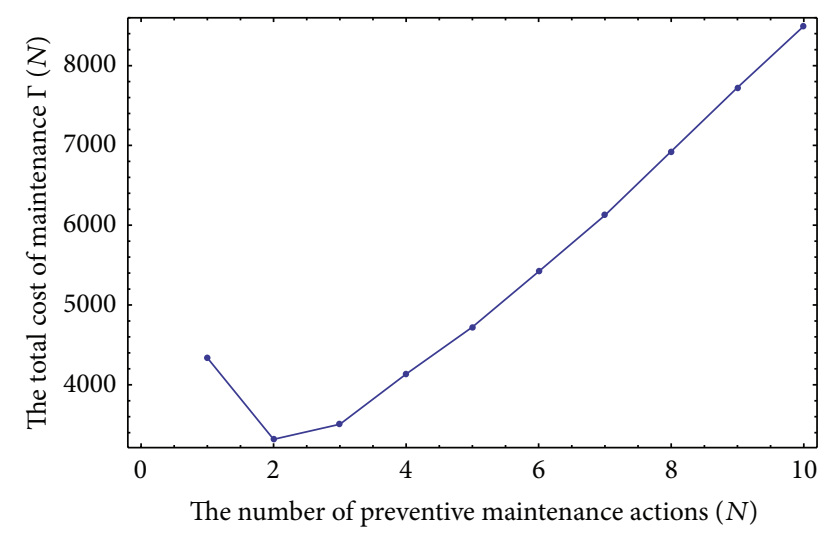

FIGURE 6: The total cost of maintenance depending to $N$.

TABLE 4: The sensitivity study based on the variation of production rate.

\begin{tabular}{lcc}
\hline & $\Gamma^{*}(N)(\mathrm{um})$ & $N^{*}$ (times) \\
\hline $\begin{array}{l}\text { Case 1: considering variation of } \\
\text { production rate }\end{array}$ & 3316 & 2 \\
\hline $\begin{array}{l}\text { Case 2: not considering the variation of } \\
\text { production rate }\end{array}$ & 3704 & 3 \\
\hline
\end{tabular}

the variation of production rate we have obtained $N^{*}=$ 2 and $\Gamma^{*}(N)=3316 \mathrm{mu}$. We can easily note that we have reduced the optimal number of preventive maintenance with performing an economical gain estimated at $10 \%$.

Several studies have addressed issues related to production and maintenance problem. But, the consideration of the materiel degradation according to the production rate in the case of multiple-product has been rarely studied.

This study was conducted to deal with the problem of an optimal production and maintenance planning for a manufacturing system. The significance of the present study is that we took into account the influence of the production plan on the system degradation in order to establish an optimal maintenance strategy. The considered system is composed of a single machine which produces several products in order to meet corresponding several random demands.

\section{Conclusion}

In this paper, we have discussed the problem of integrated maintenance to production for a manufacturing system consisting of a single machine which produces several types of products to satisfy several random demands. As the machine is subject to random failures, preventive maintenance actions are considered in order to improve its reliability. At failure, a minimal repair is carried out to restore the system into the operating state without changing its failure rate.

At first we have formulated a stochastic production problem. To solve this problem, we have used a production policy to achieve a level of economic output. This policy is characterized by the transformation of the problem to a deterministic equivalent problem in order to obtain the economic production plan. In the second step, taking into account the economic production plan obtained, we have studied and optimized the maintenance policy. This policy is defined by preventive actions carried out at constant time intervals. The objective of this policy is to determine the optimal number of preventive maintenance and the optimal intervention periods over a finite horizon. This policy is characterized by a failure rate for a linear degradation of the equipment considering the influence of production rate variation on the system degradation and on the optimal maintenance plan in the case of multiple products represents.

The promising results obtained in this thesis can lead to interesting perspectives. A perspective that we are looking for at the short term, is to consider maintenance durations. We recall that, throughout our study, we neglected the durations of actions of preventive and corrective maintenance. It is clear that the consideration of these durations impacts the optimal maintenance plan and the established production plan. In the medium term, it is interesting to concretely consider the impact of logistics service on the study. It is clear that the in-maintenance logistics are absent in most researches. The combination of maintenance logistics and production represents a motivating perspective in this field of study.

Another interesting perspective specifying the manufactured product can be explored.

\section{Appendices}

\section{A. Expression of the Total Production and Storage Cost}

We have

$Z(U)$

$$
\begin{gathered}
=\sum_{k=1}^{H} \sum_{j=1}^{p} \sum_{i=1}^{n}\left[y_{i, j, k} \times\left(\operatorname{St}(i)+\left(\operatorname{Cp}(i) \times E\left[\left(U_{i, j, k}\right)^{2}\right]\right)\right)\right. \\
+\left(\operatorname{Cs}(i) \times \frac{\delta t_{(k \times p)-(p-j)}}{\Delta t}\right. \\
\left.\left.\times E\left[\left(S_{i,(k \times p)-(p-j)}\right)^{2}\right]\right)\right],
\end{gathered}
$$




$$
\begin{aligned}
S_{i,(k \times p)-(p-j)}= & S_{i,(k \times p)-(p-j)-1}+\left(y_{i, j, k} \times U_{i, j, k}\right) \\
& -\operatorname{Int}\left[\frac{j}{p}\right] \times d_{i}(k),
\end{aligned}
$$

$\forall\{i=1, \ldots, n\},\{j=1, \ldots, p\},\{k=1, \ldots, H\}$.

Also,

$$
\begin{aligned}
\widehat{S}_{i,(k \times p)-(p-j)}= & \widehat{S}_{i,(k \times p)-(p-j)-1}+\left(y_{i, j, k} \times U_{i, j, k}\right) \\
& -\operatorname{Ent}\left[\frac{j}{p}\right] \times \widehat{d}_{i}(k)
\end{aligned}
$$

$\forall\{i=1, \ldots, n\},\{j=1, \ldots, p\},\{k=1, \ldots, H\}$.

Therefore,

$$
\begin{aligned}
& E\left[\left(S_{i,(k \times p)-(p-j)}-\widehat{S}_{i,(k \times p)-(p-j)}\right)^{2}\right] \\
& =E\left[\left(\left[S_{i,(k \times p)-(p-j)-1}+\left(y_{i, j, k} \times U_{i, j, k}\right)\right.\right.\right. \\
& \left.-\operatorname{Ent}\left[\frac{j}{p}\right] \times d_{i}(k)\right] \\
& -\left[\widehat{S}_{i,(k \times p)-(p-j)-1}+\left(y_{i, j, k} \times U_{i, j, k}\right)\right. \\
& \left.\left.\left.-\operatorname{Ent}\left[\frac{j}{p}\right] \times \widehat{d}_{i}(k)\right]\right)^{2}\right] \\
& \Longrightarrow E\left[\left(S_{i,(k \times p)-(p-j)}-\widehat{S}_{i,(k \times p)-(p-j)}\right)^{2}\right] \\
& =E\left[\left(\left[S_{i,(k \times p)-(p-j)-1}-\widehat{S}_{i,(k \times p)-(p-j)-1}\right]\right.\right. \\
& \left.\left.-\left[\operatorname{Ent}\left[\frac{j}{p}\right] \times\left(d_{i}(k)-\widehat{d}_{i}(k)\right)\right]\right)^{2}\right] \\
& \Longrightarrow E\left[\left(S_{i,(k \times p)-(p-j)}-\widetilde{S}_{i,(k \times p)-(p-j)}\right)^{2}\right] \\
& =E\left[\left(S_{i,(k \times p)-(p-j)-1}-\widetilde{S}_{i,(k \times p)-(p-j)-1}\right)^{2}\right. \\
& -2 \times\left[\left(S_{i,(k \times p)-(p-j)-1}-\widetilde{S}_{i,(k \times p)-(p-j)-1}\right)\right. \\
& \left.\times\left(\operatorname{Ent}\left[\frac{j}{p}\right] \times\left(d_{i}(k)-\widehat{d}_{i}(k)\right)\right)\right] \\
& \left.+\left(\operatorname{Ent}\left[\frac{j}{p}\right] \times\left(d_{i}(k)-\widehat{d}_{i}(k)\right)\right)^{2}\right]
\end{aligned}
$$

$$
\begin{gathered}
\Longrightarrow E\left[\left(S_{i,(k \times p)-(p-j)}-\widehat{S}_{i,(k \times p)-(p-j)}\right)^{2}\right] \\
=\left[E\left[\left(S_{i,(k \times p)-(p-j)-1}-\widehat{S}_{i,(k \times p)-(p-j)-1}\right)^{2}\right]\right. \\
-2 \times E\left[\left(S_{i,(k \times p)-(p-j)-1}-\widehat{S}_{i,(k \times p)-(p-j)-1}\right)\right. \\
\left.\quad \times\left(\operatorname{Ent}\left[\frac{j}{p}\right] \times\left(d_{i}(k)-\widehat{d}_{i}(k)\right)\right)\right] \\
\left.+E\left[\left(\operatorname{Ent}\left[\frac{j}{p}\right] \times\left(d_{i}(k)-\widehat{d}_{i}(k)\right)\right)^{2}\right]\right] .
\end{gathered}
$$

$S_{i,(k \times p)-(p-j)-1}$ and $d_{i}(k)$ are independent random variables, so we can deduce

$$
\begin{aligned}
& E\left[\left(S_{i,(k \times p)-(p-j)}-\widehat{S}_{i,(k \times p)-(p-j)}\right)^{2}\right] \\
& =\left[E\left[\left(S_{i,(k \times p)-(p-j)-1}-\widehat{S}_{i,(k \times p)-(p-j)-1}\right)^{2}\right]\right. \\
& \quad-2 \times E\left[\left(S_{i,(k \times p)-(p-j)-1}-\widehat{S}_{i,(k \times p)-(p-j)-1}\right)\right] \\
& \quad \times E\left[\left(\operatorname{Ent}\left[\frac{j}{p}\right] \times\left(d_{i}(k)-\widehat{d}_{i}(k)\right)\right)\right] \\
& \left.+E\left[\left(\operatorname{Ent}\left[\frac{j}{p}\right] \times\left(d_{i}(k)-\widehat{d}_{i}(k)\right)\right)^{2}\right]\right] .
\end{aligned}
$$

On the other hand, we note that

$$
\begin{aligned}
E & {\left[\left(S_{i,(k \times p)-(p-j)-1}-\widehat{S}_{i,(k \times p)-(p-j)-1}\right)\right] } \\
& =E\left[\left(S_{i,(k \times p)-(p-j)-1}\right)\right]-E\left[\left(\widehat{S}_{i,(k \times p)-(p-j)-1}\right)\right]=0 .
\end{aligned}
$$

Therefore,

$$
\begin{aligned}
E & {\left[\left(S_{i,(k \times p)-(p-j)}-\widehat{S}_{i,(k \times p)-(p-j)}\right)^{2}\right] } \\
= & {\left[E\left[\left(S_{i,(k \times p)-(p-j)-1}-\widehat{S}_{i,(k \times p)-(p-j)-1}\right)^{2}\right]\right.} \\
& \left.+\left(\operatorname{Ent}\left[\frac{j}{p}\right]\right)^{2} \times E\left[\left(d_{i}(k)-\widehat{d}_{i}(k)\right)^{2}\right]\right] .
\end{aligned}
$$

We know that

$$
\begin{gathered}
E\left[\left(x_{k}-\widehat{x}_{k}\right)^{2}\right]=\operatorname{Var}\left(x_{k}\right), \\
\left(\operatorname{Int}\left[\frac{j}{p}\right]\right)^{2}=\operatorname{Int}\left[\frac{j}{p}\right], \quad \text { because } 0 \leq \frac{j}{p} \leq 1 .
\end{gathered}
$$

Therefore,

$$
\begin{aligned}
E & {\left[\left(S_{i,(k \times p)-(p-j)}-\widehat{S}_{i,(k \times p)-(p-j)}\right)^{2}\right] } \\
& =\operatorname{Var}\left(S_{i,(k \times p)-(p-j)-1}\right)+\operatorname{Ent}\left[\frac{j}{p}\right] \times \operatorname{Var}\left(d_{i}(k)\right) .
\end{aligned}
$$


Finally,

$$
\begin{aligned}
\operatorname{Var}\left(S_{i,(k \times p)-(p-j)}\right)= & \operatorname{Var}\left(S_{i,(k \times p)-(p-j)-1}\right) \\
& +\operatorname{Ent}\left[\frac{j}{p}\right] \times \operatorname{Var}\left(d_{i}(k)\right) .
\end{aligned}
$$

\section{Consequently,}

(i) for $k=1$,

$$
\text { (a) } j=1 \text { : }
$$$$
\operatorname{Var}\left(S_{i, 1}\right)=\operatorname{Var}\left(S_{i, 0}\right)+\left(\operatorname{Ent}\left[\frac{1}{p}\right]\right) \times \operatorname{Var}\left(d_{i}(1)\right)
$$

(b) $j=2$ :

$\operatorname{Var}\left(S_{i, 2}\right)=\operatorname{Var}\left(S_{i, 0}\right)+\sum_{l=1}^{2} \operatorname{Ent}\left[\frac{l}{p}\right] \times \operatorname{Var}\left(d_{i}(1)\right)$

(c) $j=p$ :

$$
\operatorname{Var}\left(S_{i, p}\right)=\operatorname{Var}\left(S_{i, 0}\right)+\sum_{l=1}^{p} \operatorname{Ent}\left[\frac{l}{p}\right] \times \operatorname{Var}\left(d_{i}(1)\right)
$$

(ii) for $k=2$,

(a) $j=1$ :

$$
\begin{aligned}
\operatorname{Var}\left(S_{i, p+1}\right)= & {\left[\operatorname{Var}\left(S_{i, 0}\right)+\sum_{l=1}^{p} \operatorname{Ent}\left[\frac{l}{p}\right] \times \operatorname{Var}\left(d_{i}(1)\right)\right.} \\
& \left.+\operatorname{Ent}\left[\frac{1}{p}\right] \times \operatorname{Var}\left(d_{i}(2)\right)\right],
\end{aligned}
$$

(b) $j=2$ :

$$
\begin{aligned}
\operatorname{Var}\left(S_{i, p+2}\right)= & {\left[\operatorname{Var}\left(S_{i, 0}\right)+\sum_{l=1}^{p} \operatorname{Ent}\left[\frac{l}{p}\right]\right.} \\
& \times \operatorname{Var}\left(d_{i}(1)\right)+\operatorname{Ent}\left[\frac{1}{p}\right] \\
& \left.\times \operatorname{Var}\left(d_{i}(2)\right)+\operatorname{Ent}\left[\frac{2}{p}\right] \times \operatorname{Var}\left(d_{i}(2)\right)\right],
\end{aligned}
$$

(c) $j=p$ :

$$
\begin{aligned}
\operatorname{Var}\left(S_{i,(2 \times p)}\right)= & {\left[\operatorname{Var}\left(S_{i, 0}\right)+\sum_{l=1}^{p} \operatorname{Ent}\left[\frac{l}{p}\right] \times \operatorname{Var}\left(d_{i}(1)\right)\right.} \\
& \left.+\sum_{l=1}^{P} \operatorname{Ent}\left[\frac{l}{p}\right] \times \operatorname{Var}\left(d_{i}(p)\right)\right],
\end{aligned}
$$

(iii) for any value of $k$,

$$
\text { (a) } j=1 \text { : }
$$

$$
\begin{aligned}
\operatorname{Var}\left(S_{i,(k \times p)-(p-1)}\right)= & {\left[\operatorname{Var}\left(S_{i, 0}\right)+\sum_{Q=1}^{k-1} \sum_{l=1}^{p} \operatorname{Ent}\left[\frac{l}{p}\right]\right.} \\
& \times \operatorname{Var}\left(d_{i}(Q)\right) \\
& \left.+\sum_{l=1}^{1} \operatorname{Ent}\left[\frac{l}{p}\right] \times \operatorname{Var}\left(d_{i}(k)\right)\right],
\end{aligned}
$$

(b) $j=2$ :

$$
\begin{aligned}
\operatorname{Var}\left(S_{i,(k \times p)-(p-2)}\right)= & {\left[\operatorname{Var}\left(S_{i, 0}\right)+\sum_{Q=1}^{k-1} \sum_{l=1}^{p} \operatorname{Ent}\left[\frac{l}{p}\right]\right.} \\
& \times \operatorname{Var}\left(d_{i}(Q)\right) \\
& \left.+\sum_{l=1}^{2} \operatorname{Ent}\left[\frac{l}{p}\right] \times \operatorname{Var}\left(d_{i}(k)\right)\right]
\end{aligned}
$$

(c) for any value of $j$,

$$
\begin{aligned}
\Longrightarrow & \operatorname{Var}\left(S_{i,(k \times p)-(p-j)}\right) \\
= & {\left[\operatorname{Var}\left(S_{i, 0}\right)+\sum_{Q=1}^{k-1} \sum_{l=1}^{p} \operatorname{Ent}\left[\frac{l}{p}\right] \times \operatorname{Var}\left(d_{i}(Q)\right)\right.} \\
& \left.+\sum_{l=1}^{j} \operatorname{Ent}\left[\frac{l}{p}\right] \times \operatorname{Var}\left(d_{i}(k)\right)\right] .
\end{aligned}
$$

On the other hand,

$$
\begin{aligned}
E[ & \left.\left(S_{i,(k \times p)-(p-j)}-\widehat{S}_{i,(k \times p)-(p-j)}\right)^{2}\right] \\
=E & {\left[\left(S_{i,(k \times p)-(p-j)}\right)^{2}-2 \times S_{i,(k \times p)-(p-j)}\right.} \\
& \left.\times \widehat{S}_{i,(k \times p)-(p-j)}+\left(\widehat{S}_{i,(k \times p)-(p-j)}\right)^{2}\right] \\
\Longrightarrow E & {\left[\left(S_{i,(k \times p)-(p-j)}-\widehat{S}_{i,(k \times p)-(p-j)}\right)^{2}\right] } \\
= & {\left[E\left[\left(S_{i,(k \times p)-(p-j)}\right)^{2}\right]\right.} \\
& -E\left[2 \times S_{i,(k \times p)-(p-j)} \times \widehat{S}_{i,(k \times p)-(p-j)}\right] \\
& \left.+E\left[\left(\widehat{S}_{i,(k \times p)-(p-j)}\right)^{2}\right]\right] .
\end{aligned}
$$

We know that

$$
E\left[\left(\widehat{S}_{i,(k \times p)-(p-j)}\right)^{2}\right]=\left(\widehat{S}_{i,(k \times p)-(p-j)}\right)^{2} .
$$


Hence,

$$
\begin{aligned}
\Longrightarrow & E\left[\left(S_{i,(k \times p)-(p-j)}-\widehat{S}_{i,(k \times p)-(p-j)}\right)^{2}\right] \\
= & {\left[E\left[\left(S_{i,(k \times p)-(p-j)}\right)^{2}\right]-2 \times \widehat{S}_{i,(k \times p)-(p-j)}\right.} \\
& \left.\times E\left[S_{i,(k \times p)-(p-j)}\right]+\left(\widehat{S}_{i,(k \times p)-(p-j)}\right)^{2}\right], \\
E\left[S_{i,(k \times p)-(p-j)}\right]=\widehat{S}_{i,(k \times p)-(p-j)} & \\
\Longrightarrow & E\left[\left(S_{i,(k \times p)-(p-j)}-\widehat{S}_{i,(k \times p)-(p-j)}\right)^{2}\right] \\
= & {\left[E\left[\left(S_{i,(k \times p)-(p-j)}\right)^{2}\right]-2 \times\left(\widehat{S}_{i,(k \times p)-(p-j)}\right)^{2}\right.} \\
& \left.\times E\left[\left(S_{i,(k \times p)-(p-j)}\right)^{2}\right]+\left(\widehat{S}_{i,(k \times p)-(p-j)}\right)^{2}\right] .
\end{aligned}
$$

Consequently,

$$
\begin{aligned}
& E\left[\left(S_{i,(k \times p)-(p-j)}-\widehat{S}_{i,(k \times p)-(p-j)}\right)^{2}\right] \\
& \quad=E\left[\left(S_{i,(k \times p)-(p-j)}\right)^{2}\right]-\left(\widehat{S}_{i,(k \times p)-(p-j)}\right)^{2} .
\end{aligned}
$$

Noting that

$$
\begin{aligned}
& E\left[\left(S_{i,(k \times p)-(p-j)}-\widehat{S}_{i,(k \times p)-(p-j)}\right)^{2}\right] \\
& =\operatorname{Var}\left(S_{i,(k \times p)-(p-j)}\right) \\
& \Longrightarrow \operatorname{Var}\left(S_{i,(k \times p)-(p-j)}\right) \\
& =E\left[\left(S_{i,(k \times p)-(p-j)}\right)^{2}\right]-\left(\widehat{S}_{i,(k \times p)-(p-j)}\right)^{2},
\end{aligned}
$$

we deduce from (A.18) and (A.23) that

$$
\begin{aligned}
E[ & \left.\left(S_{i,(k \times p)-(p-j)}\right)^{2}\right]-\left(\widehat{S}_{i,(k \times p)-(p-j)}\right)^{2} \\
= & {\left[\operatorname{Var}\left(S_{i, 0}\right)+\sum_{\mathrm{Q}=1}^{k-1} \sum_{l=1}^{p} \operatorname{Ent}\left[\frac{l}{p}\right] \times \operatorname{Var}\left(d_{i}(Q)\right)\right.} \\
& \left.+\sum_{l=1}^{j} \operatorname{Ent}\left[\frac{l}{p}\right] \times \operatorname{Var}\left(d_{i}(k)\right)\right] \\
\Longrightarrow & E\left[\left(S_{i,(k \times p)-(p-j)}\right)^{2}\right] \\
= & {\left[\begin{array}{l}
\operatorname{Var}\left(S_{i, 0}\right)+\sum_{Q=1}^{k-1} \sum_{l=1}^{p} \operatorname{Ent}\left[\frac{l}{p}\right] \times \operatorname{Var}\left(d_{i}(Q)\right) \\
\end{array}\right.} \\
& \left.+\sum_{l=1}^{j} \operatorname{Ent}\left[\frac{l}{p}\right] \times \operatorname{Var}\left(d_{i}(k)\right)+\left(\widehat{S}_{i,(k \times p)-(p-j)}\right)^{2}\right] .
\end{aligned}
$$

Consequently,

$$
\begin{aligned}
E & {\left[\left(S_{i,(k \times p)-(p-j)}\right)^{2}\right] } \\
= & {\left[\sigma^{2}\left(S_{i, 0}\right)+\sum_{Q=1}^{k-1} \sum_{l=1}^{p} \operatorname{Ent}\left[\frac{l}{p}\right] \times \sigma^{2}\left(d_{i}(Q)\right)\right.} \\
& \left.\quad+\sum_{l=1}^{j} \operatorname{Ent}\left[\frac{l}{p}\right] \times \sigma^{2}\left(d_{i}(k)\right)+\left(\widehat{S}_{i,(k \times p)-(p-j)}\right)^{2}\right] .
\end{aligned}
$$

Substituting (A.25) in the expected cost expression (9),

$$
\begin{aligned}
Z(U)=\sum_{k=1}^{H} \sum_{j=1}^{P} \sum_{i=1}^{n}\left\{y_{i, j, k} \times\left(\operatorname{St}(i)+\left(\operatorname{Cp}(i) \times U^{2}{ }_{i, j, k}\right)\right)\right. \\
+\operatorname{Cs}(i) \times \frac{\delta_{(k \times p)-(p-j)}}{\Delta t} \\
\times\left[\sigma^{2}\left(S_{i, 0}\right)\right. \\
+\left(\sum_{Q=1}^{k-1} \sum_{l=1}^{p} \operatorname{Int}\left(\frac{l}{p}\right) \times \sigma^{2}\left(d_{i}(Q)\right)\right) \\
+\left(\sum_{l=1}^{j} \operatorname{Int}\left(\frac{l}{p}\right) \times \sigma^{2}\left(d_{i}(k)\right)\right) \\
\left.\left.+\left(\widehat{S}_{i,(k \times p)-(p-j)}\right)^{2}\right]\right\} .
\end{aligned}
$$

\section{B. Expression of Failure Rate}

Equation (A.9) is expressed as follows for the different subperiods:

(i) for $k=1$,

(a) $j=1$ :

$$
\lambda_{1}(t)=\left(\lambda_{0}\right) \times\left(1-\operatorname{In}\left[\frac{0}{q \times T}\right]\right)+\sum_{i=1}^{n} \frac{U_{i, 1,1} \times \Delta t}{U_{i \mathrm{nom}} \times \delta_{1}} \times \lambda_{n}(t),
$$

(b) $j=2$ :

$$
\begin{aligned}
\lambda_{2}(t)= & \lambda_{1}\left(\delta_{1}\right) \times\left(1-\operatorname{In}\left[\frac{1}{q \times T}\right]\right) \\
& +\sum_{i=1}^{n} \frac{U_{i, 2,1} \times \Delta t}{U_{i \mathrm{nom}} \times \delta_{2}} \times \lambda_{n}(t),
\end{aligned}
$$




$$
\begin{aligned}
\lambda_{2}(t)= & \left(\lambda_{0}+\sum_{i=1}^{n} \frac{U_{i, 1,1} \times \Delta t}{U_{i \text { nom }} \times \delta_{1}} \times \lambda_{n}\left(\delta_{(1)}\right)\right) \\
& \times\left(1-\operatorname{In}\left[\frac{1}{q \times T}\right]\right)+\sum_{i=1}^{n} \frac{U_{i, 2,1} \times \Delta t}{U_{i \text { nom }} \times \delta_{2}} \times \lambda_{n}(t),
\end{aligned}
$$

(c) $j=p$ :

$$
\begin{aligned}
\lambda_{p}(t)= & \left(\lambda_{p-1}\left(\delta_{p-1}\right)\right) \times\left(1-\operatorname{In}\left[\frac{p-1}{q \times T}\right]\right) \\
& +\sum_{i=1}^{n} \frac{U_{i, p, 1} \times \Delta t}{U_{i \text { nom }} \times \delta_{p}} \times \lambda_{n}(t), \\
\lambda_{p}(t)= & {\left[\left(\lambda_{0}+\sum_{l=1}^{p-1} \sum_{i=1}^{n} \frac{U_{i, l, 1} \times \Delta t}{U_{i \text { nom }} \times \delta_{l}} \times \lambda_{n}\left(\delta_{(l)}\right)\right)\right.} \\
& \left.\times\left(1-\operatorname{In}\left[\frac{p-1}{q \times T}\right]\right)+\sum_{i=1}^{n} \frac{U_{i, p, 1} \times \Delta t}{U_{i \text { nom }} \times \delta_{p}} \times \lambda_{n}(t)\right],
\end{aligned}
$$

(ii) for any value of $k$,

$$
\text { (a) } j=1 \text { : }
$$

$$
\begin{aligned}
\lambda_{((k-1) \times p)+1}(t) & {\left[\left(\lambda_{(k-1) \times p}\left(\delta_{(k-1) \times p}\right)\right) \times\left(1-\operatorname{In}\left[\frac{((k-1) \times p)}{q \times T}\right]\right)\right.} \\
& \left.+\sum_{i=1}^{n} \frac{U_{i, 1, k} \times \Delta t}{U_{i \text { nom }} \times \delta_{((k-1) \times p)+1}} \times \lambda_{n}(t)\right] \\
\lambda_{((k-1) \times p)+1}(t) & {\left[\left(\lambda_{0}+\sum_{\mathrm{Q}=1}^{k-1} \sum_{l=1}^{p} \sum_{i=1}^{n} \frac{U_{i, l, Q} \times \Delta t}{U_{i n o m} \times \delta_{(Q \times p)-(p-l)}}\right.\right.} \\
& \left.\quad \times \lambda_{n}\left(\delta_{(\mathrm{Q} \times p)-(p-l)}\right)\right) \\
& \left.+\sum_{i=1}^{n} \frac{U_{i, 1, k} \times \Delta t}{U_{i \text { nom }} \times \delta_{((k-1) \times p)+1}} \times \lambda_{n}(t)\right] \\
& \quad\left(1-\operatorname{In}\left[\frac{((k-1) \times p)}{q \times T}\right]\right)
\end{aligned}
$$

(b) for any value of $j$,

$$
\begin{aligned}
& \lambda_{(k \times p)-(p-j)}(t) {\left[\left(\lambda_{0}+\sum_{Q=1}^{k-1} \sum_{l=1}^{p} \sum_{i=1}^{n} \frac{U_{i, l, Q} \times \Delta t}{U_{i \text { nom }} \times \delta_{(Q \times p)-(p-l)}}\right.\right.} \\
& \times \lambda_{n}\left(\delta_{(Q \times p)-(p-l)}\right) \\
&+\sum_{l=1}^{j-1} \sum_{i=1}^{n} \frac{U_{i, l, k} \times \Delta t}{U_{i \text { nom }} \times \delta_{(k \times p)-(p-l)}} \\
&\left.\times \lambda_{n}\left(\delta_{(k \times p)-(p-l)}\right)\right) \\
& \times\left(1-\text { In }\left[\frac{(k \times p)-(p-j+1)}{q \times T}\right]\right) \\
&\left.+\sum_{i=1}^{n} \frac{U_{i, j, k} \times \Delta t}{U_{i \text { nom }} \times \delta_{(k \times p)-(p-j)}} \times \lambda_{n}(t)\right] \\
& t \in\left[0, \delta_{(k \times p)-(p-j)}\right] \quad \forall\{k=1, \ldots, H\},\{j=1, \ldots, p\} .
\end{aligned}
$$

\section{Conflict of Interests}

The authors declare that there is no conflict of interests regarding the publication of this paper.

\section{References}

[1] O. S. S. Filho, "Stochastic production planning problem under unobserved inventory system," in Proceedings of the American Control Conference (ACC '07), pp. 3342-3347, New York, NY, USA, July 2007.

[2] F. I. D. Nodem, J. P. Kenné, and A. Gharbi, "Simultaneous control of production, repair/replacement and preventive maintenance of deteriorating manufacturing systems," International Journal of Production Economics, vol. 134, no. 1, pp. 271-282, 2011.

[3] A. Gharbi, J.-P. Kenné, and M. Beit, "Optimal safety stocks and preventive maintenance periods in unreliable manufacturing systems," International Journal of Production Economics, vol. 107, no. 2, pp. 422-434, 2007.

[4] N. Rezg, S. Dellagi, and A. Chelbi, "Optimal strategy of inventory control and preventive maintenance," International Journal of Production Research, vol. 46, no. 19, pp. 5349-5365, 2008.

[5] J. P. Kenne, E. K. Boukas, and A. Gharbi, "Control of production and corrective maintenance rates in a multiple-machine, multiple-product manufacturing system," Mathematical and Computer Modelling, vol. 38, no. 3-4, pp. 351-365, 2003.

[6] W. Feng, L. Zheng, and J. Li, "The robustness of scheduling policies in multi-product manufacturing systems with sequence-dependent setup times and finite buffers," Computers and Industrial Engineering, vol. 63, no. 4, pp. 1145-1153, 2012. 
[7] T. W. Sloan and J. G. Shanthikumar, "Combined production and maintenance scheduling for a multiple-product, singlemachine production system," Production and Operations Management, vol. 9, no. 4, pp. 379-399, 2000.

[8] O. S. S. Filho, "A constrained stochastic production planning problem with imperfect information of inventory," in Proceedings of the 16th IFAC World Congress, vol. 2005, Elsevier Science, Prague, Czech Republic.

[9] Z. Hajej, S. Dellagi, and N. Rezg, "An optimal production/maintenance planning under stochastic random demand, service level and failure rate," in Proceedings of the IEEE International Conference on Automation Science and Engineering (CASE '09), pp. 292-297, Bangalore, India, August 2009.

[10] Z. Hajej, Contribution au développement de politiques de maintenance intégrée avec prise en compte du droit de rétractation et du remanufacturing [Thèse de doctorat], Université Paul Verlaine, Metz, France, 2010.

[11] Z. Hajej, S. Dellagi, and N. Rezg, "Optimal integrated maintenance/production policy for randomly failing systems with variable failure rate," International Journal of Production Research, vol. 49, no. 19, pp. 5695-5712, 2011.

[12] J. P. Kenne and L. J. Nkeungoue, "Simultaneous control of production, preventive and corrective maintenance rates of a failure-prone manufacturing system," Applied Numerical Mathematics, vol. 58, no. 2, pp. 180-194, 2008.

[13] T. Nakagawa and S. Mizutani, "A summary of maintenance policies for a finite interval," Reliability Engineering and System Safety, vol. 94, no. 1, pp. 89-96, 2009. 


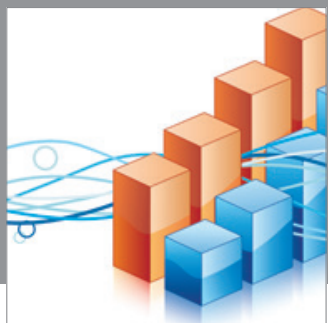

Advances in

Operations Research

mansans

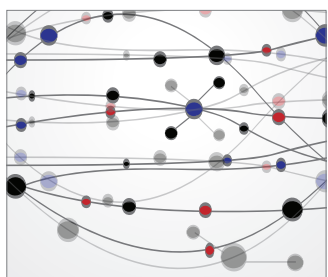

The Scientific World Journal
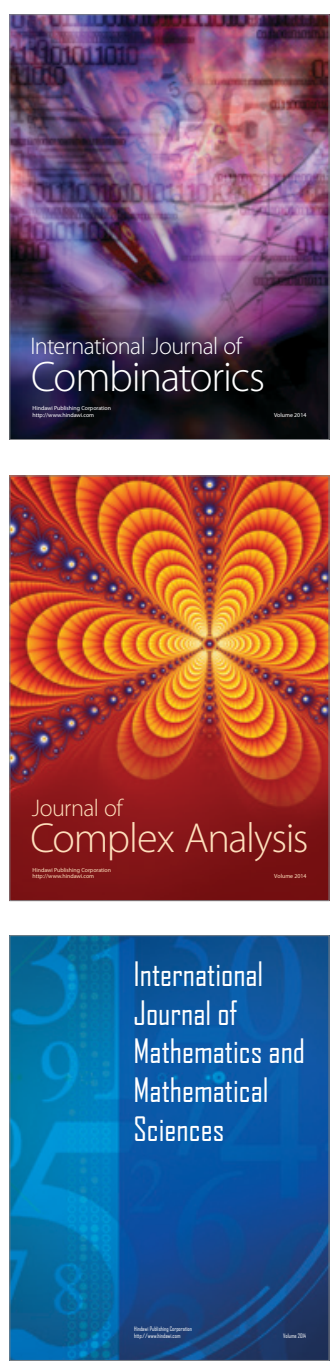
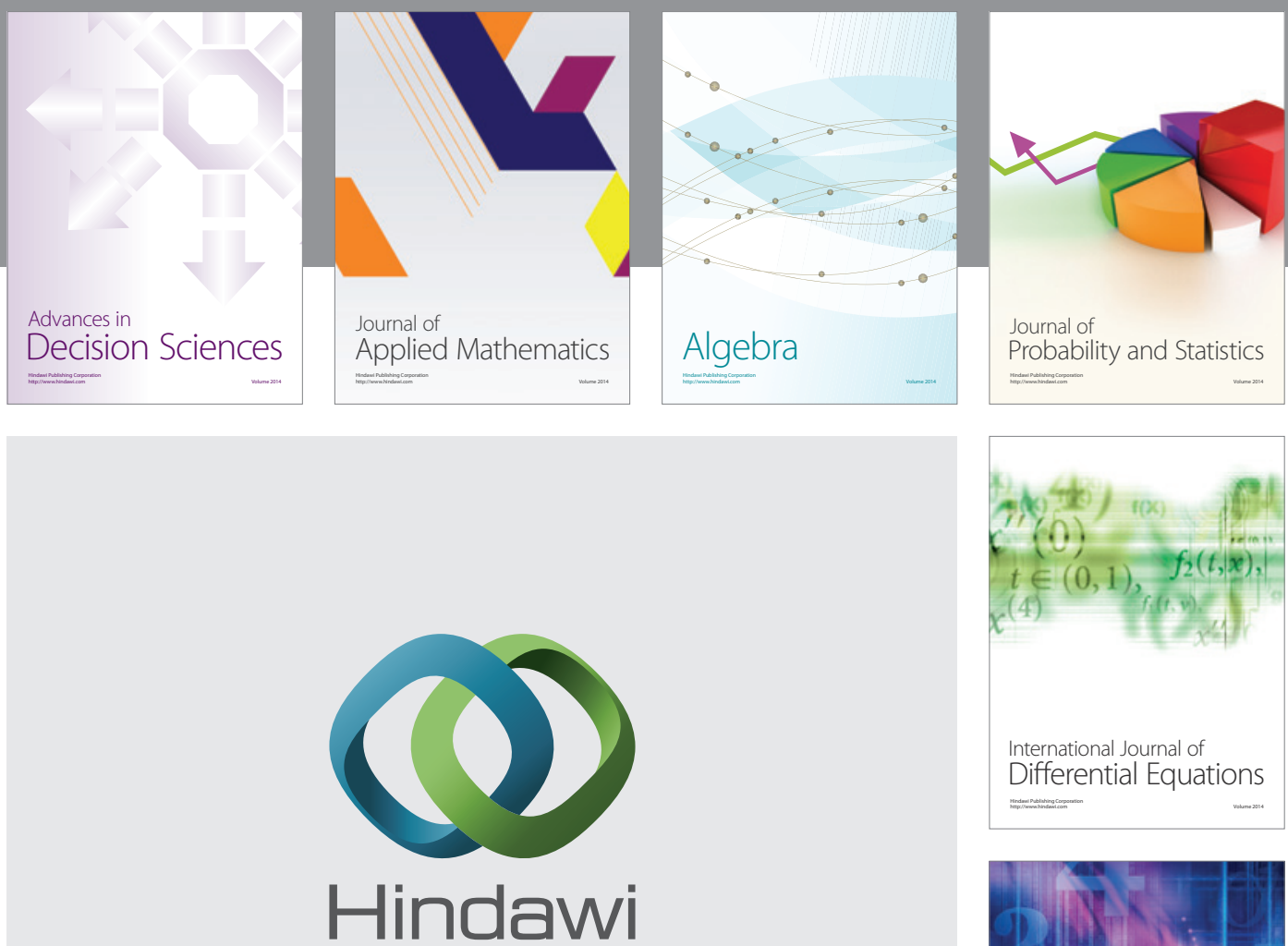

Submit your manuscripts at http://www.hindawi.com
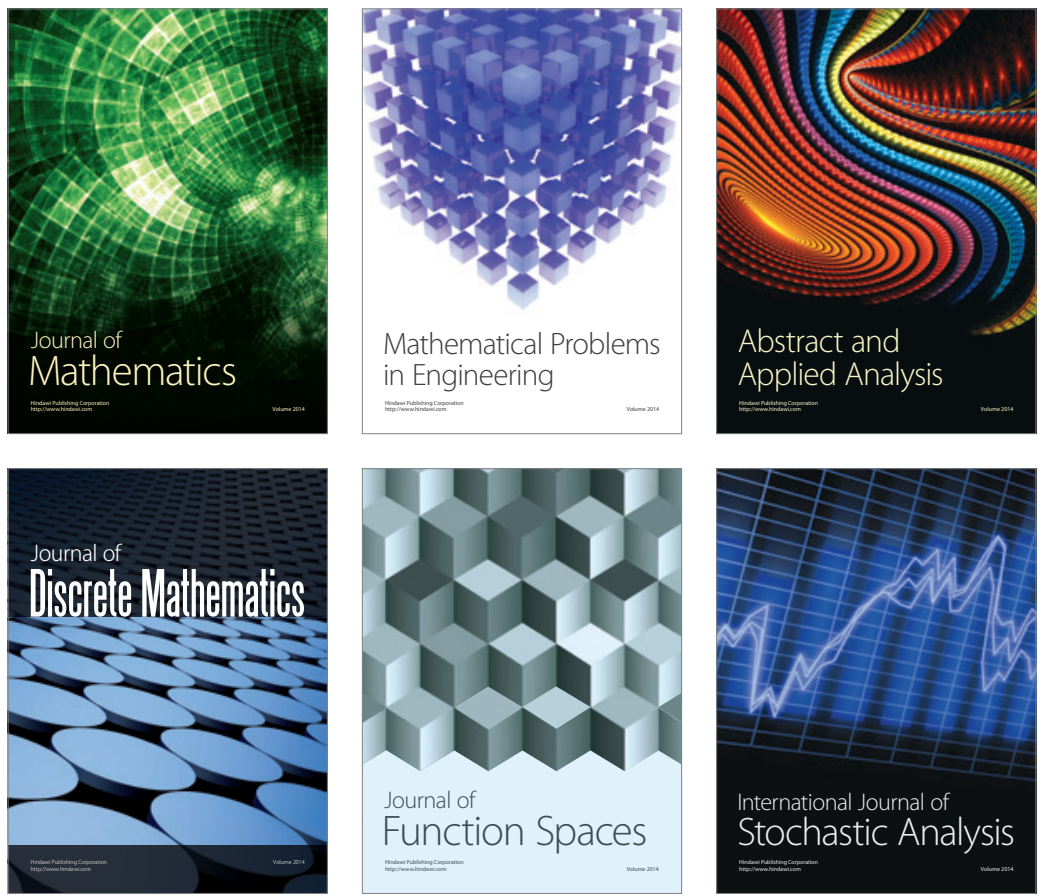

Journal of

Function Spaces

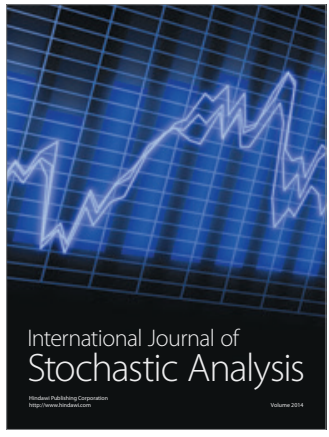

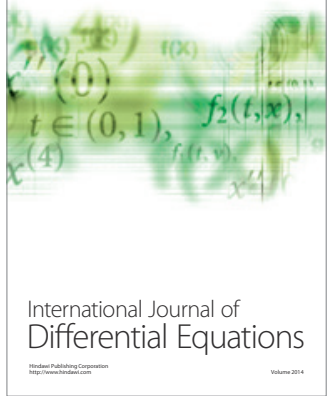
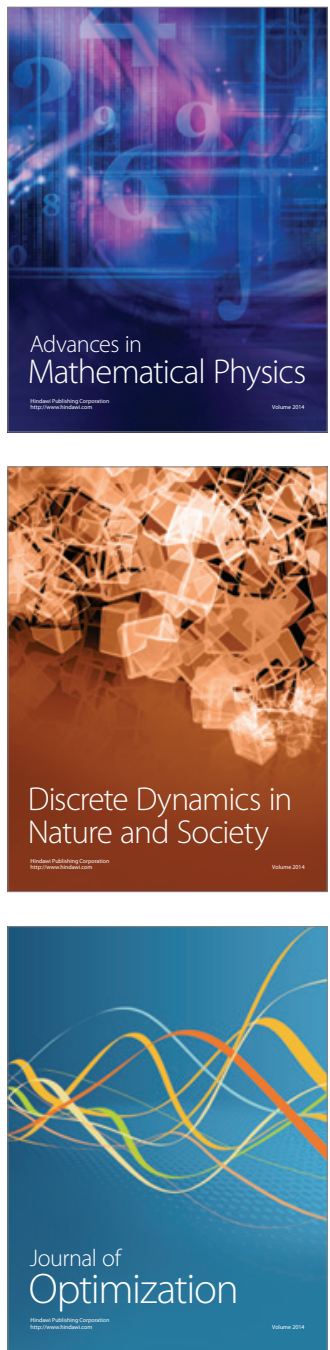